\title{
Reagent Removal of Heavy Metals From Waters of Coal Mines and Spoil Tips of the Lviv-Volyn Industrial Mine Region
}

\author{
Oksana Mazurak", Irina Solovodzinska', Andriy Mazurak², Nataliia Gryncyhshyn² \\ 1 Department of Ecology, Lviv National Agrarian University 1, V.Velykogo St., 30831 Dubliany, Lviv region, \\ Ukraine \\ 2 Department of Building and Architecture, Lviv National Agrarian University 1, V.Velykogo St., 30831 Dubliany, \\ Lviv region, Ukraine \\ ${ }^{3}$ Department of ecological safety, Lviv State University of Life Safety, 35, Kleparivska St., 79007, Lviv, Ukraine \\ * Corresponding author's e-mail: mazurak.oksana1969@gmail.com
}

\begin{abstract}
The article substantiates the efficiency of using chemical (reagent) technologies for the purification of industrial water from mines and spoil tips from heavy metals-toxicants and reducing their ecological hazard. The ecological risk indices of toxicants and their proportion in the overall level of ecological danger of the investigated object were presented. The results of experimental studies, interaction of comparative qualitative indicators of removal of heavy metal ions by inorganic reagents - calcium carbonate and sodium hydroxide were provided. It is shown that the solution of the ecological problem concerning the reduction of the toxicity level of subterminal waters of mines is their treatment with fine calcium carbonate $\mathrm{CaCO}_{3}$ that converts the heavy metal ions into hardly soluble basic carbonates or heavy metal hydroxides. Positive results concerning the efficiency of the subterminal water treatment of the «Velikomostovskaya» mine of the Chervonograd mining area by calcium carbonate were identified. That indicates a significant reduction of the ecological hazard indicator of the treated wastewater. The content of ions of most heavy metals, which precipitate in the form of basic carbonates at values close to $\mathrm{pH}=8.5$, was significantly reduced.
\end{abstract}

Keywords: ecological hazard, heavy metals, toxicants, mine, calcium carbonate, sodium hydroxide.

\section{INTRODUCTION}

There is ecological problem of mine drainage and ground subsidence, especially in inhabited areas, as a result of the mining activity in the Lviv-Volyn industrial mine region (Fig. 1), and in particular, the mines of the Chervonograd region. The subsidence of the bottom surface (depth ranging from 0.6 to $3.9 \mathrm{~m}$ ) is accompanied by processes of flooding and soils waterlogging. Every year, 5.0 to 10 million $\mathrm{m}^{3}$ of polluted mine waters is pumped from mines of the basin, the toxic effects of which appear at all local biocenoses covering area of about $90 \mathrm{~km}^{2}$, where 4770 hectares of farmland and 642 hectares of forest areas were destroyed. The territories of the city of Chervonograd, the villages of Sielets and Mezhirichchia are flooded almost completely, which makes building drainage systems, pumping out of water and carrying out sand pouring of flooded territories a necessity.

Highly mineralized metal-containing components of wastewaters from under spoil of mines and spoil tips of the Chervonograd region cause a significant degradation of the soil layer of surrounding territories, contamination of underground aquifers, migration and assimilation of toxic compounds of heavy metals at almost all levels of the environment [Adamenko et al. 2016; Buchatska 2009] Hence, the minimization of the role of the natural geological barrier is taking place and the natural systems are unabled to perform self-rehabilitation [Dong et al. 2011; Knysh and Karabin 2010]. The lack 
of universal methods for the utilization of mine and sub-spoil waters in case of unreliability of their accounting, low efficiency of purification methods, and their selectivity necessitate conducting a study onthe chemistry of heavy metal binding reactions in order to create optimal conditions for their immobilization and reduce the level of toxicity of spoil mine waters [Dlamini at al. 2013; Myung 2008]. One of the main technogenic sources of influence on underground, surface waters, soils and natural biocenoses is the mine waters and spoil tips of "Velikomostovskaya» mine the department of «Lvivvugillya State Enterprise».

The purpose of the work is to study the peculiarities, mechanisms and efficiency of the chemical processes for the chemical removal of heavy metal toxicants $\left(\mathrm{Cu}^{2+}, \mathrm{Mn}^{2+}, \mathrm{Pb}^{2+}, \mathrm{Co}^{2+}, \mathrm{Cd}^{2+}, \mathrm{Zn}^{2+}\right.$, $\left.\mathrm{C}^{\mathrm{r} 3+}, \mathrm{Fe}_{\text {total. }}, \mathrm{Hg}^{2+}\right)$ from mine waters of «Velikomostovskaya» mine and calculation of the proportion of each pollutant component in the level of environmental hazard of the investigated object.

\section{MATERIALS}

In order to reduce the toxicity of mine and spoil tip waters, reagents capable of converting heavy metal ions into sparingly soluble compounds were used - finely dispersed calcium carbonate $\left(\mathrm{CaCO}_{3}\right)$ powder and $0.95 \mathrm{~N}$ sodium hydroxide $(\mathrm{NaOH})$ solution.

Calcium carbonate is finely dispersed powder of white color, made by grinding marble crumb. Calcium carbonate $\left(\mathrm{CaCO}_{3}\right)$ constitutes solid crystals of white color, practically insoluble in water (at $20^{\circ} \mathrm{C}, \mathrm{K}_{\mathrm{s}}=0.00066 \mathrm{~g} / 100 \mathrm{~g}$ of $\mathrm{H}_{2} \mathrm{O}$ ). The molar mass of $\mathrm{CaCO}_{3}$ equals 100.087 $\mathrm{g} / \mathrm{mol}$. Melting point $+825^{\circ} \mathrm{C}$, decomposition temperature $+1300^{\circ} \mathrm{C}$. The density is $2.83 \mathrm{~g} /$ $\mathrm{cm}^{3}$. The mass fraction of calcium carbonate in the resulting powder is $98.6 \%$; magnesium carbonate is $0.7 \%$ by weight, about $0.1 \% \mathrm{Fe}_{2} \mathrm{O}_{3}$, and silicon compounds. The mass residual fraction on 200 microns sieve amounts to $0.5 \%$, while on 45 microns $-63.0 \%$. Inorganic and organic impurities, fibers or inclusions of other materials were not detected. It occurs in the form of mineral compounds - calcite, aragonite, and vaterite [Volkov and Zharsky 2005].

Another chemical agent $-0.95 \mathrm{~N}$ sodium hydroxide solution was used. The molar mass of $\mathrm{NaOH}=39.997 \mathrm{~g} / \mathrm{mol}$. Melting point $+323^{\circ} \mathrm{C}$. Boiling point $+1388{ }^{\circ} \mathrm{C}$. Density $-2.13 \mathrm{~g} / \mathrm{cm}^{3}$. Solubility in water at $25^{\circ} \mathrm{C}$ is $108.7 \mathrm{~g} / 100 \mathrm{~g}$. Sodium hydroxide (caustic soda) is available in two types: solid and liquid. Solid granular caustic soda is a white solid matter with a granule size about $0.5-2 \mathrm{~cm}$. The caustic soda is very hygroscopic, well soluble in water, when exposed to water, a large amount of heat is released. A solution of sodium hydroxide is a solution of the secondary standard, so the study was conducted with fresh $\mathrm{NaOH}$ solution. Liquid caustic soda is a colorless or colored liquid - sodium hydroxide, technical, GOST 2263-79. By degree of influence on the body, it refers to the substances of the 2nd class of danger [Nabivanets 1996; Volkov and Zharsky 2005].

\section{METHODS AND PROCEDURE}

The studies on the mine water were carried out at laboratory of the State Environmental Inspection of Lviv region in the Department of instrumental-laboratory and radiation control in accordance with current methods and standards [Standard methods for the examination of water and wastewater 2006; Guiding normative documents of the Ministry of Environmental Protection of Ukraine 2006].

Sampling, storage and handling of water samples was carried out in accordance with DSTU

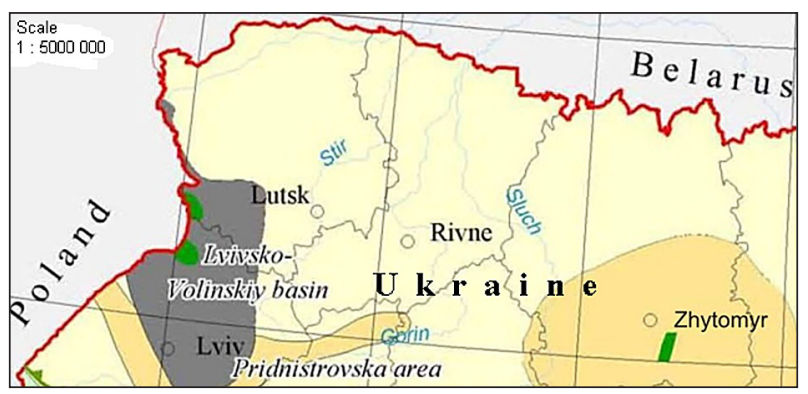

Fig. 1. Map of the Lviv-Volyn industrial mine region 
ISO 5667-6-2001 and DSTU ISO 5667-10-2001

[Derzhspozhyvstandart of Ukraine 2006].

The total iron content, zinc and nickel were determined with the method of photometric analysis. The titrimetric method of analysis was used to detect and determine calcium, magnesium and chlorides in water. Sulfates were determined by means of the gravimetric method. The mass concentration of heavy metals in the samples of mine waters was determined with the flame atomic absorption spectrophotometry.

Sampling and chemical analysis of soils were carried out in accordance with the procedure of DSTU 4770.1-9: 2007 at the certified laboratory of Lviv department of State Agency «Gosgruntohorona». The preparation of solutions of soil extracts was carried out in accordance with DSTU 4770.9: 2007. The content of mobile forms of heavy metals in soil samples was determined on atomic absorption spectrophotometer C-115 [Safarova V. at al. 2011; Zhou and Guo 2015].

For the complex evaluation of the ecological condition of the territory around the «Velikomostovskaya» mine, the results of the chemical analyses of mine waters from 2005 to 2015 years, which were performed in the laboratory of SE «Lvivvugillya», results of our own investigations over the past three years and results of regional hydrogeochemical investigations of scientists on the specified topics were used [Samchuk 2009; Knysh and Karabin 2010; Voytovich 2015].

Mathematical and statistical methods were employed to calculate the changes in concentrations of chemicals (heavy metals, sulfate and chloride anions) in the waters of the spoil tips during the period of research. As statistical parameters of distribution, the central characteristics (arithmetic mean and median), variation indices and maximum concentrations of the substances dissolved in water in the samples during the representative period of statistical aggregate data of concentrations of pollutants were calculated in the work.

The «EXCEL» software was used to process the statistical parameters and the software package «Statistica 6.0» was employed for the visualization of results [Borovikov and Ivchenko 1999].

Quantitative analyses of the ecological hazard index $(E H)$ of pollutants, in particular of heavy metals, i.e., exceeding the normative concentration for fish ponds and their proportion in the overall level of environmental hazard $(W)$ were calculated with the formula:

$$
\begin{gathered}
W=\frac{C / M P C}{\sum E H} \times 100 \% \\
E H=\frac{C}{M P C},
\end{gathered}
$$

where: $C$ - concentration of pollutants (at the place of sampling), $\mathrm{mg} / \mathrm{dm}^{3}$;

$M P C$ - the maximum permissible concentration of pollutants for fish ponds; $\Sigma E H$ - a total index of the environmental hazard of all pollutants.

\section{RESULTS AND DISCUSSION}

The production capacity of the «Velikomostovskaya» mine on 01.01 .2018 is 300 thousand tons per year. The mine occupies an area of 648 hectares, including 346 hectares of agricultural land, 242 hectares of settlements and 60 hectares of other territories. The location of the «Velikomostovskaya» mine (1 VM - the old name), the other 8 operating and 4 non-operating mines (1 CHR, 2 VM, 5 VM, 8 VM) and the spoil tips on the explored territory indicate that they are still sources of pollution of water [Buchatska 2009], since the active waste of contaminated sewage in the river Western Bug and rivers of its basin was observed from the tips and territories of the mines (Fig. 2, Fig. 3).

The distribution of mine water is determined by the geological structure, hydrogeological conditions and tectonic features of the territory, as well as a set of basic natural factors that determine the patterns of formation, distribution and composition of the mine waters. Thus, the high content of calcium ions and sulfate ions in the waters of the «Velikomostovskaya» mine can be explained by the presence of tectonic fractures in this and adjoining territories, which are transmitted by cretaceous waters in carbonic water, which changes the qualitative and quantitative characteristics of coal-water [Matlock et al. 2002; Samchuk 2009.].

Integrated hydrochemical research, conducted in the period 2016-2018 in the zone of influence of the Chervonograd mines showed a significant content of toxic heavy metal ions in tip waters, as well as chlorides and sulfates, which contribute to the acidic environment of mine waters.

Clayey rocks of argillites, the content of which accounts for about $70 \%$ of waste, and a significant amount of sulfur (the transformation 


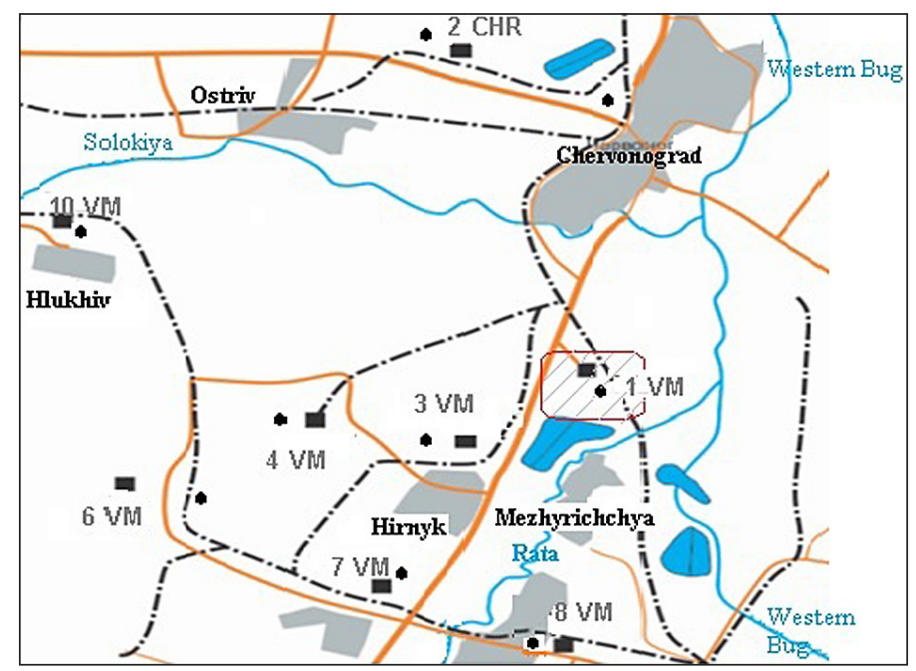

Fig. 2. Map diagram of the Chervonograd mining area (1 VM - «Velikomostovskaya» mine)

a)

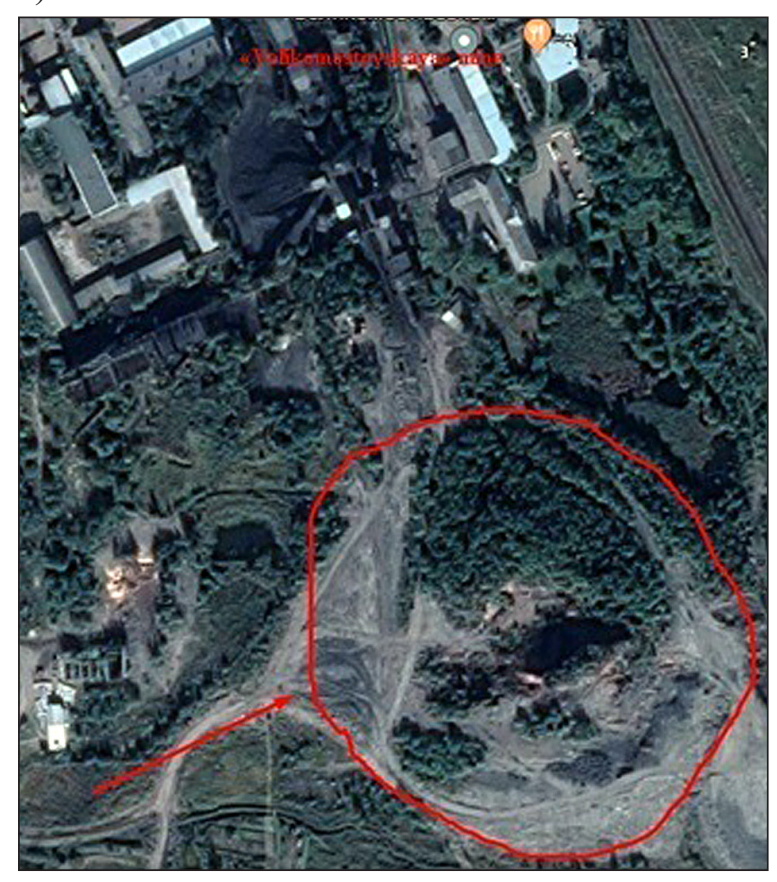

b)

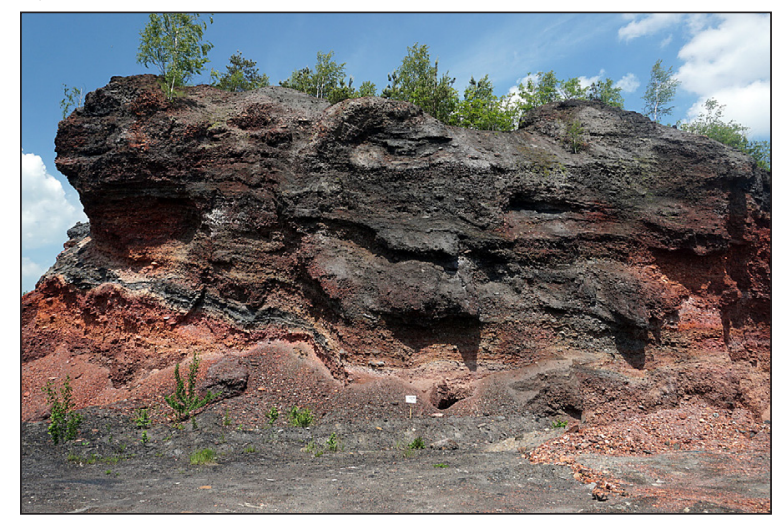

c)

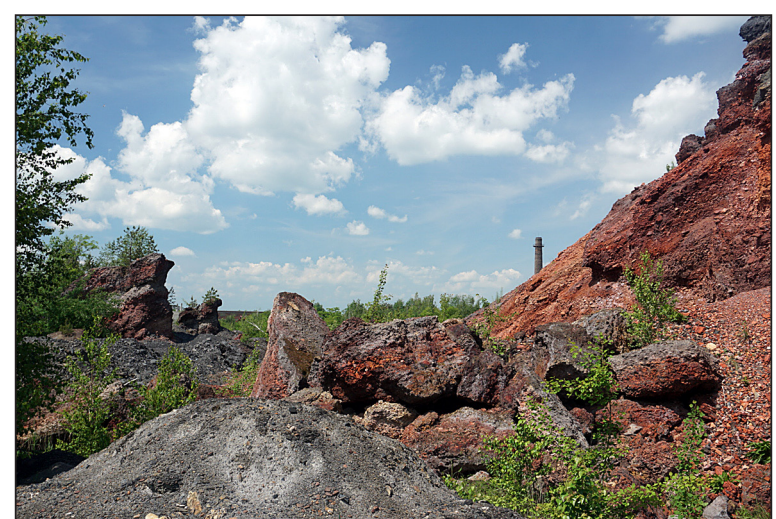

Fig. 3. Photos of «Velikomostovskaya» mine (a) and a spoil tips of «Velikomostovskaya» mine (b, c) 
of sulfides in sulfates) contribute to the formation of oreol of acidic waters at the foot of the spoil tips, the migration and sorption of heavy metal ions [Tobylko 2016], prolongation of their effect in the environment. At the same time, lowering of the $\mathrm{pH}$ values of spoil tips waters as well as periodic changes in the temperature lead to the transition of compounds of heavy metals from sorbent to mineral and organic substances into free state [Knysh and Karabin 2010; Keng et al. 2014].

The results of investigations on the content of pollutants in the spoil tips waters of the "Vosmonstovskaya» mine of «Lvivvugillya» indicate an excess of the parameters of the MPC of heavy metals, anions of strong acid-electrolytes for the fish ponds (Table 1).

The calculated index of exceeding the normative values of each pollutant component (C/MPC) and the percentage of its excess $(W)$ in relation to the overall level of environmental hazard $(E H)$ of all pollutants for the spoil tip waters of the «Velikomostovskaya» mine $\left(E H=6,274 \times 10^{3}\right)$ indicate its high ecological danger to the environment.

The maximum contribution to the overall level of pollution is made by the water of the mine containing manganese (about 96\%). Due to the high mineralization of underground waters and the hydrolysis of heavy metal salts, the release of strong acids (sulfate and chloride) into the medium occurs. In the investigated area, the type of mine waters is predominantly chloridehydrocarbonate-sodium with mineralization from 2.5 to $9 \mathrm{~g} / \mathrm{dm}^{3}$. The slightly acidic environment of the spoil tip waters of the «Velikomostovskaya» mine $(\mathrm{pH}=6.6)$ indicates the possibility of soil contamination due to the chemical processes of dissolution, oxidation-reduction and migration to the surface of heavy metal ions [Rene et al. 2017; Grishko et al. 2012.]. The composition of waters near spoil tips is saturated with anions of acids (sulfates, chlorides), as well as products of pyrite decomposition, in particular the compounds of iron, manganese, cuprum, nickel, lead, and other heavy metals ions (Table 2).

Investigation of the calcium carbonate effect on the purification of mine waters was carried out by precipitation and mixing the reagent with the subsequent determination of $\mathrm{pH}$ by the potentiometry method (to establish a stable $\mathrm{pH} \approx 6.8$ ). The results of the studies on the calcium carbonate purification efficiency spoil tips waters of «Velikomostovskaya» mine and their ecological hazard evaluation are presented in Table 3 and Figure 4.

Comparative calculations of $W$ proportion of each component in the level of ecological hazard of sewage indicate that the choice of a chemical agent $\left(\mathrm{CaCO}_{3}\right)$ for the removal of most toxic metals is correct and meets the water quality requirements for fishery reservoirs. At the same time, the concentration of sulfates also decreased significantly.

The mechanism for the removal of heavy metals $\left(\mathrm{Co}^{2+}, \mathrm{Zn}^{2+}, \mathrm{Cr}^{3+}, \mathrm{Ni}^{2+}\right)$ using hydrolyzed calcium carbonate $(\mathrm{pH} \approx 8.5)$ is simultaneous with the formation of the basic carbonates of these metals, the solubility of which is lower than that of neutral carbonates (except highly soluble alkali salts and hydroxides $\mathrm{Cd}^{2+}, \mathrm{Pb}^{2+}, \mathrm{Mn}^{2+}$ ). The minimum solubility of metal hydroxides is observed in alkaline media at $\mathrm{pH}>8.5$ (except $\mathrm{Fe}^{3+}$ ions) [Nabivanets 1996; Pestrikov et al. 2009].

Table 1. The content of pollutants in the spoil tips waters of «Velikomostovskaya» mine

\begin{tabular}{|c|c|c|c|c|c|}
\hline No & Polutant & MPC, $\mathrm{mg} / \mathrm{l}$ & Concentra-tion, $\mathrm{mg} / \mathrm{l}$ & $\mathrm{C} / \mathrm{MPC}$ & $\mathrm{W}, \%$ \\
\hline 1 & $\mathrm{Fe}_{\text {total }}$ & 0,1 & 5,836 & 58 & 0,9 \\
\hline 2 & $\mathrm{Mn}(2+)$ & 0,01 & 59,97 & 5997 & 95,6 \\
\hline 3 & $\mathrm{Cu}(2+)$ & 0,001 & 0,040 & 40,3 & 0,6 \\
\hline 4 & $\mathrm{~Pb}(2+)$ & 0,01 & 0,133 & 13 & 0,21 \\
\hline 5 & $\mathrm{Cd}(2+)$ & 0,0005 & 0,021 & 42 & 0,67 \\
\hline 6 & $\mathrm{Zn}(2+)$ & 0,01 & 0,148 & 14,8 & 0,24 \\
\hline 7 & $\mathrm{Cr}(3+)$ & 0,005 & 0,032 & 6,4 & 0,64 \\
\hline 8 & $\mathrm{Ni}(2+)$ & 0,01 & 0,401 & 16 & 0,26 \\
\hline 9 & $\mathrm{Co}(2+)$ & 0,01 & 0,159 & 1,8 & 0.02 \\
\hline 10 & $\mathrm{Chlorides}$ & 300 & 524,9 & 24,5 & 0,39 \\
\hline 11 & $\mathrm{Sulfates}$ & 100 & 2449.66 & 3,3 & 0,053 \\
\hline 12 & $\mathrm{Ca}(2+)$ & 180 & 591,18 & 17 & 0,27 \\
\hline 13 & $\mathrm{Mg}(2+)$ & 40 & 687,04 & & 100 \\
\hline \multicolumn{7}{|c|}{} \\
\hline
\end{tabular}


Table 2. The content of water soluble and total heavy metals in soils near the spoil tips of «Velikomostovskaya» mine

\begin{tabular}{|c|c|c|c|}
\hline No & Polutant & Content of water soluble form, $\mathrm{mg} / \mathrm{kg}$ & $\begin{array}{c}\text { The content of total heavy metals, } \mathrm{mg} / \\
\mathrm{kg}\end{array}$ \\
\hline 1 & $\mathrm{Fe}_{\text {total. }}$ & 0,05 & 16,2 \\
\hline 2 & $\mathrm{Mn}(2+)$ & 28,5 & 181,4 \\
\hline 3 & $\mathrm{Cu}(2+)$ & 0,02 & 1,3 \\
\hline 4 & $\mathrm{~Pb}(2+)$ & 0,06 & 5,9 \\
\hline 5 & $\mathrm{Cd}(2+)$ & 0,018 & 0,27 \\
\hline 6 & $\mathrm{Zn}(2+)$ & 0,03 & 0,24 \\
\hline 7 & $\mathrm{Cr}(3+)$ & 0,01 & 2,8 \\
\hline 8 & $\mathrm{Ni}(2+)$ & 0,9 & 4,6 \\
\hline 9 & $\mathrm{Co}(2+)$ & 0,09 & 0,14 \\
\hline 10 & $\mathrm{Hg}(2+)$ & - & 0,026 \\
\hline 11 & $\mathrm{Chlorides}$ & 283 & - \\
\hline 12 & Sulfates & 163 & - \\
\hline
\end{tabular}

Table 3. Efficiency of purification of calcium carbonate of underground waters of «Velikomostovskaya» mine and their environmental hazard

\begin{tabular}{|c|c|c|c|c|}
\hline No & Polutant & Degree of purification, $\%$ & $\mathrm{C} / \mathrm{MPC}$ & $\mathrm{W}, \%$ \\
\hline 1 & $\mathrm{Fe}_{\text {total }}$ & 99,9 & - & - \\
\hline 2 & $\mathrm{Mn}(2+)$ & 75,1 & 1494 & 98,5 \\
\hline 3 & $\mathrm{Cu}(2+)$ & 99,8 & - & - \\
\hline 4 & $\mathrm{~Pb}(2+)$ & 94,6 & - & - \\
\hline 5 & $\mathrm{Cd}(2+)$ & 98 & - & - \\
\hline 6 & $\mathrm{Zn}(2+)$ & 99,3 & - & - \\
\hline 7 & $\mathrm{Cr}(3+)$ & 93,3 & - & - \\
\hline 8 & $\mathrm{Ni}(2+)$ & 96,3 & 1,5 & 0,1 \\
\hline 9 & Co $(2+)$ & 91,3 & 1,4 & 0,1 \\
\hline 10 & Chlorides & 0 & 1,8 & 0,07 \\
\hline 11 & Sulfates & 99,9 & 0,01 & - \\
\hline 12 & $\mathrm{Ca}(2+)$ & 6,1 & 3,1 & 0,2 \\
\hline 13 & $\mathrm{Mg}(2+)$ & 2 & 16,8 & 1,1 \\
\hline \multicolumn{3}{|c|}{ Total index of the environmental hazard $\Sigma E H$} & 1518 & 100 \\
\hline
\end{tabular}

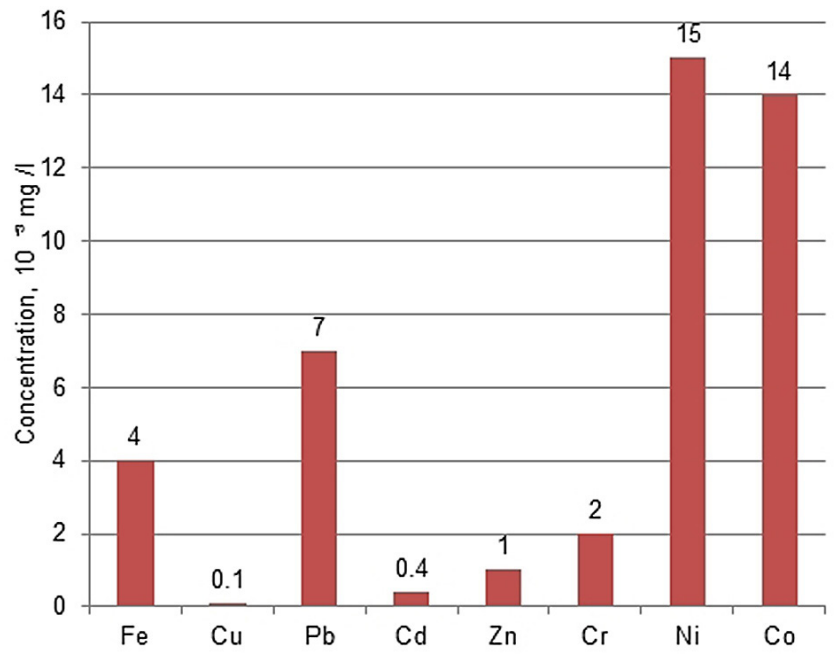

Fig. 4. Concentration of heavy metal ions after treatment by calcium carbonate 
The results of studies on the efficiency of cleaning and environmental hazards of the underground waters of the «Velikomostovskaya» mine indicate that the content of heavy metal ions and sulfates after treatment by fine-dispersed calcium carbonate has significantly decreased. The estimated value of the ecological hazard indicator amounts to $E H=1518$ for the purified $\mathrm{CaCO}_{3}$ tip waters (Table 3 ), which is four times less than the initial value $(E H=6274)$ (Table 1$)$.

Manganium ions $\mathrm{Mn}^{2+}(98,5 \%)$ are the most important environmental hazard in mine waters, which is explained by the peculiarities of their hydrolysis, precipitation and the formation of oxides, hydroxides, or complex compounds at different degrees of oxidation $(+2 \div+4)$ of ions, depending on the oxidation-reduction potential of the medium, temperature and concentration of hydrogen and metal ions [Rene et al. 2017].

These features require the optimization of the precipitation conditions of the $\mathrm{Mn}^{2+}$ ions or the replacement of the method for increasing the degree of its removal (e.g. oxidative demagnetization: in alkaline solution by potassium permanganate, ozonation, chlorination, biochemical oxidation or biosorption [Nemati and Harison 2000; Wang and Chen 2009]).

The study of the $0.95 \mathrm{~N} \mathrm{NaOH}$ solution for purification of underground waters $\left(V_{\text {prob }}\right.$ water $\left.=100 \mathrm{ml}\right)$ of the "Velikomostovskaya» mine was carried out by fractional sedimentation until the $\mathrm{pH} \approx 6.6-6.8$ was reached, followed by filtration of the sediment. Estimation of the purification efficiency by sodium hydroxide solution pertaining to underground waters and investigation of their ecological danger is given in Table 4 and Figure 5.

The results of the research show that ions of heavy metals (ferrum, cuprum, plumbum, zinc, nickel and manganese) were removed after treatment with alkali by $98 \div 99.9 \%$ by weight, the degree of removal of $\mathrm{Ca}^{2+}$ ions was $42.7 \%$; however, the concentration of sulfate and chloride ions remained unchanged.

The overall indicator of the environmental hazard of the underground water of the mine after treatment with a solution of $\mathrm{NaOH}$ is significantly lower (157 times), compared with the initial value of this indicator of contaminated water. In addition, the indicators of environmental hazard of pollutants for the waste water purified with $\mathrm{NaOH}$ solution are 38 times lower than those treated with $\mathrm{CaCO}_{3}$. However, the indicators of residual mineralization by hydroxidation method lead to a high toxicity of mine water [Thiruvenkatachari et al. 2008], which was confirmed by the study on the radish. At the same time, after treatment of calcium carbonate wastewater, their toxicity for the seeds of plant is practically zeroed.

The effectiveness of both methods for the chemical removal of heavy metals from the spoil tip waters of the "Velikomostovskaya» mine is quite high, which enables to significantly reduce the content of heavy metals in mine water and neutralize the strong-acid medium to neutral.

In addition, the use of calcium carbonate as a chemical agent has several advantages over sodium hydroxide. Under interaction of heavy metal ions with $\mathrm{CaCO}_{3}$, less soluble basic carbonates (at lower $\mathrm{pH}$ values) are formed than hydroxides

Table 4. Efficiency of purification by sodium hydroxide of underground waters of «Velikomostovskaya» mine and their environmental hazard

\begin{tabular}{|c|c|c|c|c|}
\hline No & Polutant & Degree of purification, $\%$ & $C / M P C$ & $W, \%$ \\
\hline 1 & $\mathrm{Fe}_{\text {total }}$ & 99,9 & $0,6 \times 10^{-4}$ & - \\
\hline 2 & $\mathrm{Mn}(2+)$ & 97,5 & 0,015 & 0,04 \\
\hline 3 & $\mathrm{Cu}(2+)$ & 99,9 & 0,006 & 0,02 \\
\hline 4 & $\mathrm{~Pb} \mathrm{(2+)}$ & 99,9 & 0,001 & 0,003 \\
\hline 5 & $\mathrm{Cd}(2+)$ & 91,4 & 3,6 & 9 \\
\hline 6 & $\operatorname{Zn}(2+)$ & 99,9 & 0,014 & 0,035 \\
\hline 7 & $\operatorname{Cr}(3+)$ & 91,7 & 0,5 & 1,25 \\
\hline 8 & $\mathrm{Ni}(2+)$ & 98,4 & 0,65 & 1,63 \\
\hline 9 & Co $(2+)$ & 95 & 0,08 & 0,2 \\
\hline 10 & Chlorides & 0 & 1,08 & 2,7 \\
\hline 11 & Sulfates & 0 & 24,5 & 61,3 \\
\hline 12 & $\mathrm{Ca}(2+)$ & 42,7 & 1,88 & 4,7 \\
\hline 13 & $\mathrm{Mg}(2+)$ & 56,9 & 7,4 & 18,5 \\
\hline \multicolumn{3}{|c|}{ Total index of the environmental hazard $(\Sigma E H)$} & 40 & 100 \\
\hline
\end{tabular}




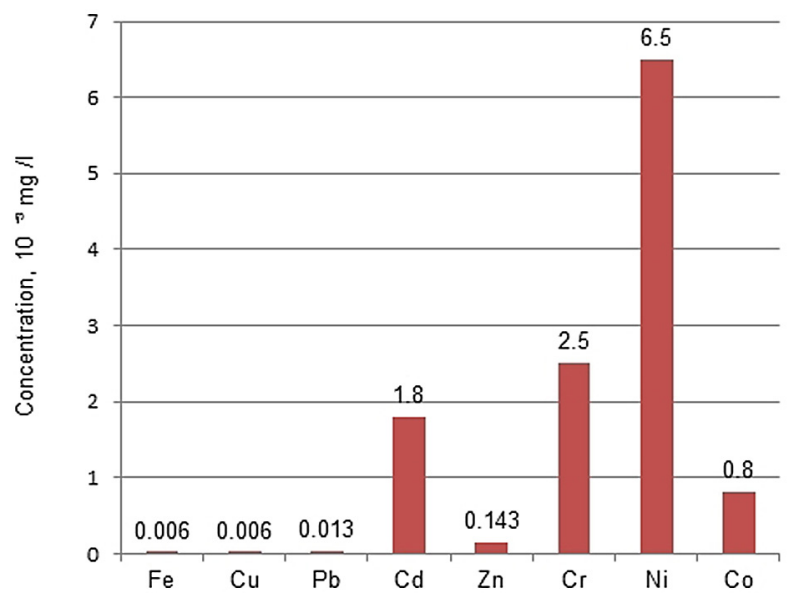

Fig. 5. Concentration of heavy metal ions after treatment by sodium hydroxide

of these metals, as well as the concentration of sulfate anions is significantly reduced. It is also important that the use of this reagent due to insignificant solubility of calcium carbonate in water is carried out in an alkaline medium at a $\mathrm{pH} \approx 8.5$, which satisfies the conditions for mine water discharges.

The advantage of this reagent is also the possibility of using inexpensive natural material [Gruszecka-Kosowska et al. 2017; Keng et al. 2014; Zasidko et al. 2019] - carbonate gravel of different sizes as a filter material for mine and spoil tip waters. Attention was drawn to the idea of applying the so-called geochemical barrier [Pestrikov et al. 2009], where mine waters will be directed after pre-settling. It is proposed to use a concrete structure of appropriate length $\mathrm{L}$, width $\mathrm{B}$ and depth $\mathrm{H}$ of a rectangular shape with recess for sedimentation and inclination for water drainage (Fig. 6). Before introducing the mine waters into carbonate barrier it is necessary to direct them to the settling tank (or use the mine space) with a waterproofing time of 5-10 days, which will ensure the efficiency of cleaning from suspended particles up to $80-90 \%$.
Carbon gravel is placed in containers from the grid; the rock can be easily regenerated (replaced) after use. The proposed geochemical carbonate barrier for further purification from toxic compounds of heavy metals may remain operational within $2-3$ years with a working life of $\approx$ $22 \%$, due to the partial consumption of calcium carbonate in ion exchange reactions.

Mine waters sediments, as well as multi-tonnage combustible waste of coal enrichment spoil tips after purification and controlling the residual concentrations of pollutants can be used as components for pigment production or alternative fuels for combustion in rotary kilns of cement production, solving the problem of waste utilization and conservation of natural resources.

\section{CONCLUSIONS}

The inflow of industrial metal-containing highly mineralized mine waters and sewage from under spoil tips leads to the negative degradation changes of the soil, natural biocenoses, deterioration of water reservoirs, etc. The role of the natural geological barrier near the rock

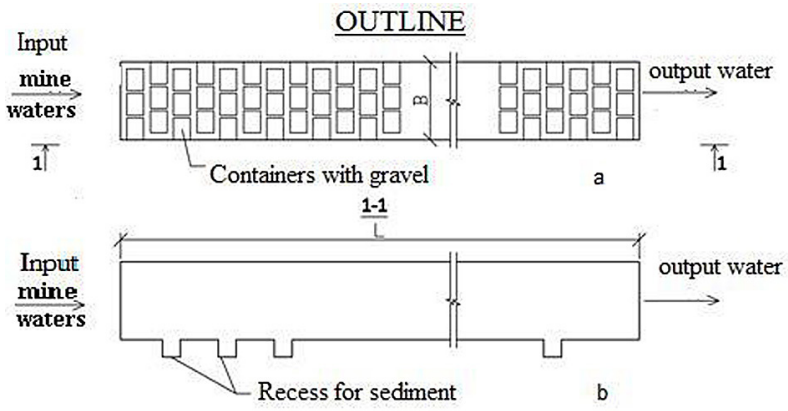

Fig. 6. Outline for carbonate geochemical barrier [16]: a - scheme; b - longitudinal section 
development sites is almost eliminated due to the anthropogenic stress, whereas there is a clear tendency for frontal migration of heavy metal ions and other pollutants through underground and surface waters to biological objects with their subsequent translocation. The evaluation of the toxicity of heavy metals, the peculiarities and conditions for the formation of various forms of pollutants should determine the specificity of their transfer into biosphere levels, the possibility of accumulation and safe utilization and/or removal from the environment.

The use of the carbonate method for the treatment of mine waters more effectively solves the problem of neutralizing anions of strong electrolytes, significantly reducing the mineralization of wastewater by binding sulfate anions $(99.9 \%)$ to insoluble calcium sulfate, as well as stabilizing the $\mathrm{pH}$ of the medium without overdose of the reagent, which corresponds to the conditions of wastewater discharges in the reservoirs. The method of reagent sedimentation of heavy metal ions by the action of $\mathrm{CaCO}_{3}$, due to its high efficiency (cheap and affordable reagent, does not require sophisticated equipment, easy to operate), can be used under uncontrolled discharges of contaminated water, and also when other methods are not possible.

\section{REFERENCES}

1. Adamenko Ya.O. et al. 2016. Territorial norm of quality of hydro eco-systems of protected territories. Hydrobiological Journal. Begell House.

2. Borovikov V. P. Ivchenko G. I. 1999. Forecasting in the STATISTICA system in the WINDOWS environment. Finance and Statistics. Moscow, 382.

3. Buchatska G. M. 2009. Hydrogeological conditions and hydrogeochemical zonation of Lviv-Volyn coal basin. Visnyk of Lviv University. Geological series, Lviv, 23. 175-183.

4. Dlamini C., Fadiran A. and Thwala J. 2013. A Study of Environmental Assessment of Acid Mine Drainage in Ngwenya, Swaziland, Journal of Environmental Protection, Vol. 4 (11B), 2013, 20-26.

5. Dong J. et al. 2011. Assessing the Concentration and Potential Dietary Risk of Heavy Metals in Vegetables at a $\mathrm{Pb} / \mathrm{Zn}$ Mine Site. China Environ. Earth Sci., 64, 1317-1321.

6. Grishko V.M. et al. 2012. Heavy metals: soil retrieval, translocation in plants and environmental safety. Donbass, Donetsk, 304.

7. Gruszecka-Kosowska A., Baran P., Wdowin M.,
Franus W. 2017. Waste dolomite powder as an adsorbent of $\mathrm{Cd}, \mathrm{Pb}(\mathrm{II})$, and $\mathrm{Zn}$ from aqueous solutions. Environ Earth Sci, 76(521), 1-12.

8. Guidelines for the sampling of sewage. Part 10. DSTU ISO 5667-10-2001. Derzhspozhyvstandart of Ukraine, Kyiv, 2006, 42.

9. Guiding normative documents of the Ministry of Environmental Protection of Ukraine, which regulate methods of determining the parameters of composition and properties of natural and sewage. GND 211.1.4. Derzhspozhyvstandart of Ukraine. 2006, Kyiv, 246.

10. Keng P. S.et al. 2014. Removal of Hazardous Heavy Metals From Aqueous Environment by Low-Cost Adsorption Materials. Civil and Environmental Engineering Faculty Publications. 100 s.

11. Knysh I.B., Karabin V. 2010. Geochemistry of trace elements in the rocks of the waste heap of the Mezhyrichanska reservoir of the Lviv-Volyn Carboniferous Basin. Geology and geochemistry of combustible minerals, 3-4 (152-153), 85-101.

12. Matlock M.M, Howerton B.S, Atwood D.A. 2002. Chemical precipitation of heavy metals from acid mine drainage. Water Res, 36, 4757-4764.

13. Myung J. 2008. Heavy Metal Concentrations in Soils and Factors Affecting Metal Uptake by Plants in the Vicinity of a Korean $\mathrm{Cu}-\mathrm{W}$ Mine. Areas of Misurata. Libya International Journal of Analytical Chemistry, Volume 2013. http://www.mdpi.org.

14. Nabivanets B. Y. 1996. Analytical chemistry of the environment. Lybid, Kyiv, 304.

15. Nemati M., Harison STL. 2000. Comparative study on thermophilic and mesophilic bioxidation of ferrous iron. Miner Eng., 13, 19-24.

16. Pestrikov S.V. et al. 2009. Geo-ecological technologies: reagent purification of metal-containing sub-water waters of the spent career Kuly-YurtTau. Engineering ecology, 3, 44-52.

17. Rene E. et al. 2017. Sustainable heavy metal remediation. V. 2: case studies. Cham, Switzerland: Springer. $278 \mathrm{p}$.

18. Samchuk A. 2009. Spatial-temporal peculiarities of the distribution of heavy metals in anthropogenized Polissya landscapes: Ukrainian Geographical Journal, 1, 19-24.

19. Safarova V. at al. 2011. Methods of Sample Preparation of Soil, Bottom Sediments, and Solid Wastes for Atomic Absorption Determination of Heavy Metals. Inorganic Materials, 2011, Vol. 47(14), 1512-1517.

20. Standard methods for the examination of water and wastewater. Washington: APHA-AWWA-WEF, 2005. 21.

21. Thiruvenkatachari, R., Vigneswaran, S., \& Naidu, 
R. 2008. Permeable reactive barrier for groundwater remediation. Journal of Industrial and Engineering Chemistry, 14 (2), 145-156.

22. Tobylko V. 2016. Development of sorption technologies for protecting water against contamination by heavy metals and radionuclides: diss. Cand. tech Sciences: 21.06.01. Kyiv. 184.

23. Volkov A., Zharsky I. Big chemical guide. Minsk: Modern School, 2005, 608.

24. Voytovich S.P. 2015. Hydrogeochemical zoning of the Chervonograd mining area: Collective. sci- ences works Kyiv. UkrDGRI. 2, 109-124.

25. Wang. J., \& Chen C. 2009. Biosorbents for heavy metals removal and their future. Biotechnology Advances, 27 (2), 195-226.

26. Zasidko I. et al. 2019. Complex technology of sewage purification from heavy-metal ions by natural adsorbents and utilization of sewage sludge. Journal of Ecological Engineering, 20(5), 209-216.

27. Zhou, H. and Guo, X. (2015). Soil Heavy Metal Pollution. Evaluation around Mine Area with Traditional and Ecological Assessment Methods. Journal of Geoscience and Environment Protection, 3, 28-33. 